\title{
Surgical Treatment Results in Craniofacial Dermoid Cysts: Retrospective Analysis of 29 Cases
}

\author{
(1) Özlem Çolak, (1) Ayberk Akçay, (D) Ayça Ergan Şahin, (1) ilker Üsçetin, (1) Özay Özkaya Mutlu \\ University of Health Sciences, Istanbul Okmeydanı Training and Research Hospital, Department of Plastic Reconstructive and Aesthetic Surgery, \\ istanbul, Turkey
}

\section{Abstract}

Objective: Dermoid cysts are developmental malformations originating from ectoderm and mesoderm. They are congenital and usually localized in the head and neck region. Their walls are covered with squamous epithelium and may contain different skin patches and tissues (multiple sebaceous glands, hair follicles, sweat glands, fat, nail, eye, teeth, cartilage). The purpose of this study was to present an approach to the masses in the head and neck region, to evaluate the relationship between preoperative imaging, final pathology and differential diagnosis, and to discuss how treatment planning should be done.

Methods: In this study, 37 patients, who admitted to our clinic for masses in the head and neck region and who underwent surgery after necessary consultations and preoperative evaluation between January 2010 and July 2017 were retrospectively reviewed. Patients were evaluated in terms of age, gender, lesion size, lesion location, preoperative imaging, intracranial involvement, treatment and complications.

Results: Of the 29 patients included in this study, 15 were male (51.7\%) and 14 were female (48.2\%). The age of the patients ranged from 1 to 28 years and the mean age was 10 years. Twenty-two of the lesions were localized on the lateral side of the eyebrows (75.8\%), two on the glabella (6.8\%), two in the temporal region (6.8\%), one in the occipital region (3.4\%), one on the forehead (3.4\%), and one in the medial canthal region (3.4\%). At the time of admission, all patients complained of swelling under the skin at the localization of the lesion. At least one imaging modality, primarily computed tomography, was requested to assess intracranial involvement in all patients' preoperatively. The main reason for the removal of lesions was cosmetic problems.

Conclusion: Dermoid cysts are operated not only for the removal of poor cosmetic appearance, but also for the prevention of possible leakage and infection, for definite pathologic diagnosis and for prevention of secondary bone changes.

Keywords: Dermoid cyst, head and neck, intracranial involvement

\section{INTRODUCTION}

Dermoid cysts are congenital malformations originated from ectoderm and mesoderm. They are usually localized on the head and neck region, and trunk. They are lined by squamous epithelium and involve different types of skin-related structures such as multiple sebaceous glands, hair follicles, sweat glands, fat, nail, teeth, cartilage or bone structure. Dermoid cysts are often benign as they contain mature tissue. Squamous cell carcinoma in adults and endodermal sinus tumor in infants and children are some rare malignant forms of dermoid cysts. Head and neck dermoid cysts constitute less than $10 \%$ of all dermoid cysts. There is no definite information on prevalence, racial selectivity and gender discrimination. However, most cases of dermoid cysts in the literature belong to the white race. In infants, they are usually found as subcutaneous masses throughout the embryonic skin fusion lines. The regions where they are commonly seen include periorbital (zygomaticofrontal suture), nasal (frontonasal suture and rhinion), intraoral (floor of the mouth), scalp (anterior fontanel and cranial sutures) and postauricular areas (1, 2). 
In this study, we aimed to retrospectively review our experience in terms of location, clinical findings and surgical treatments of dermoid cysts located in the head and neck region, to better define the characteristics of each subgroup and to establish a comprehensive treatment algorithm.

\section{METHODS}

In this study, a total of 37 patients, who were admitted to our clinic with a mass in the head and neck region, and who were operated after required consultations and preoperative evaluations between January 2010 and July 2017, were retrospectively reviewed. Patients were evaluated in terms of age, gender, size and location of lesion, preoperative imaging results, intracranial involvement, treatment and complications. Preoperative radiology reports were examined, postoperative pathology reports were obtained from the archives and patients with a definite pathology report of dermoid cyst were identified. Eight patients (22.8\%) were excluded from the study due to mismatch of the initial diagnosis and definite pathology results. In order to prevent potential complications or relapse, patients were invited for control every 3 months for at least 1 year. At the end of this period, no recurrence, pathological scar and additional complications were observed. The details, characteristics on admission and management of the patients are given in Table 1. In the direct excisional approach, the incision was made on the periorbital masses on the lateral edge of the eyebrows and in the hairline for the masses on the scalp. In unsuitable cases, an incision was made in the middle of the masses to create minimal stress. If the mass was close to a nerve, that nerve was dissected and preserved. After dissection, the mass was excised and checked for any bone or orbital extension. All excised masses were sent for pathological examination.

\section{RESULTS}

Of the 29 patients included in this study, 15 were male (51.7\%) and 14 were female (48.2\%). The ages of the patients ranged from 1 to 28 years and the mean age was 10 years. Twenty-two of the lesions were localized lateral to eyebrow (75.8\%), two were on glabella (6.8\%), two were in the temporal region (6.8\%), one was in the occipital region (3.4\%), one was on the forehead (3.4\%), and one was in the medial canthal region (3.4\%). The mean lesion size was $13.2 \times 7.03 \mathrm{~mm}$ (between 18 and $4 \mathrm{~mm}$ ). Regarding localization of the lesions, 14 (48.2\%) were on the right side, 11 (37.9\%) were on the left side and 4 (13.7\%) were midline. On admission, there was swelling under the skin at the lesion localization. No pain or discharge was reported over the lesion. In the preoperative evaluations, all patients had at least undergone one imaging modality: computed tomography (CT), ultrasonography (USG) or magnetic resonance imaging (MRI). Two patients (6.8\%) had both CT scan and MRI. Nine patients (31.03\%) had only USG, 12 patients (41.3\%) had USG and CT scan, four patients (13.7\%) had USG and MRI, and two patients (6.8\%) had USG, MRI and CT scan. Also, the comparison between initial diagnoses based on preoperative imaging and postoperative pathology results are shown in Table 2.

The main reason for the removal of the lesions was cosmetic problems. All patients were operated under general anesthesia. The lesions were excised by proper incision through the skin and the defects were closed primarily. Pathological examination of all lesions was performed. No complications were observed. All the masses were superficial and none had intradural or intracranial extension. In one patient, the mass was compressing the temporal muscle, but there was no muscle perforation or deeper penetration. In one case, the cyst was fistulated into the orbita from the lateral wall of the orbital cavity (Figures 1, 2). In one patient, the mass caused erosion of the occipital bone, and bone was trimmed and bone wax applied. No cutaneous fistula or signs of inflammation were observed. Dermoid cysts were reported in $29(82.8 \%)$ of the 37 patients operated. In the remaining eight patients, definite pathology results were not dermoid cyst despite initial dermoid cyst diagnosis according to preoperative imaging reports. In six patients (16.2\%), epidermoid cyst, in one patient (2.7\%), juvenil hemangioma and in one patient (2.7\%), pylomatrixoma were reported as definite pathology results.

\section{DISCUSSION}

Facial dermoids are generally sporadic but familial linkage has been described in the literature. There are two theories
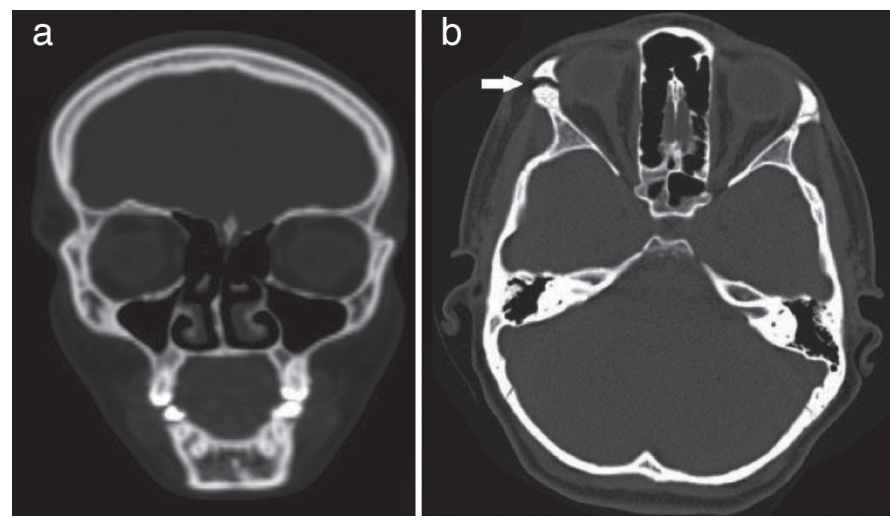

Figure 1. CT image of the dermoid cyst on the lateral right eyebrow in a 16-year-old patient. a) Coronal section, b) axial section; fistula into the orbita from the lateral wall of the right orbita (arrow) 
about the embryological origin of craniofacial dermoids The first is the superficial sequestration theory described by Bland-Sutton in 1893. The second and more widely accepted theory is the prenasal space theory described by Grunwald in 1910. This theory focuses on nasofrontal fontanelle formed by intramembranous ossification between frontal and nasal bones (2). Frontozygomatic dermoid cysts are superficial masses in zygomaticofrontal suture. They are usually removed by simple direct excision. Dermoid cysts contain histologically dermal adnexal structures such as intraluminal keratin and pilosebaceous units (3-5). Epidermal cysts are similar to dermoid
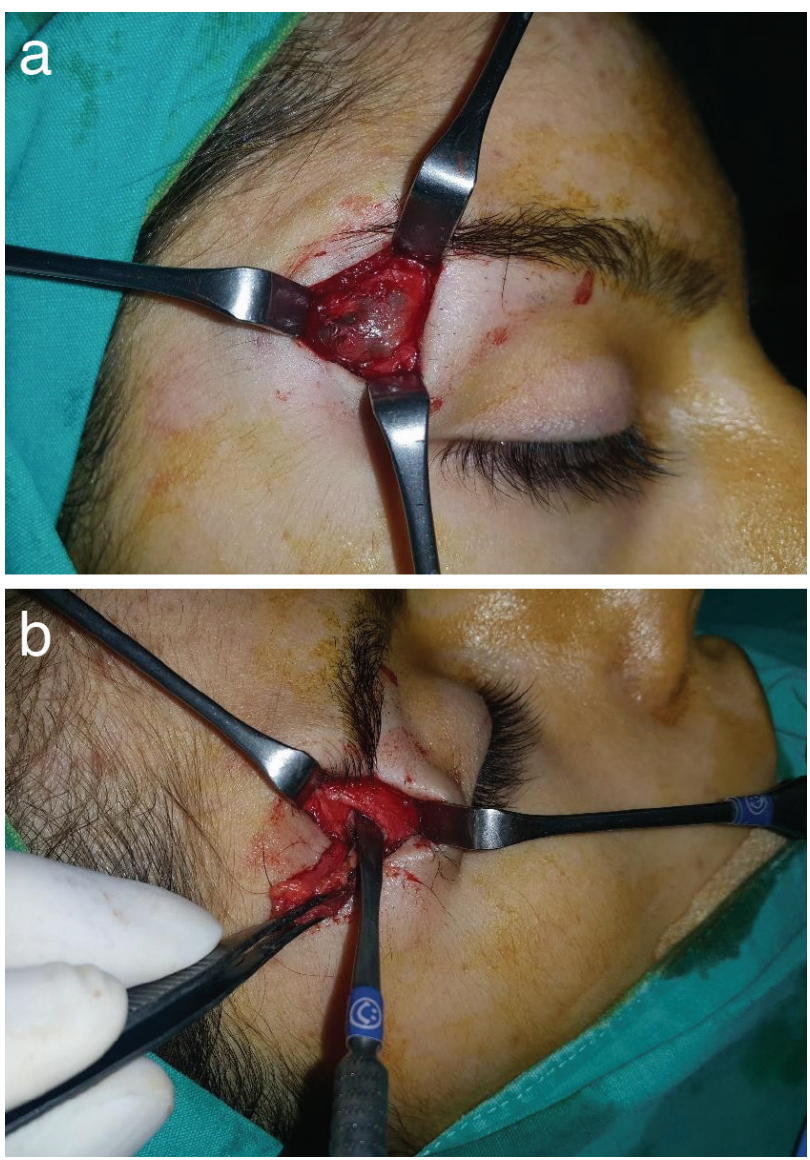

Figure 2. Peroperative photos of the patient in a) exploration of the dermoid cyst from the eyebrow incision, b) fistula into the orbita from the lateral wall during removal of the dermoid cyst cysts, but do not contain pilosebaceous units in the cyst wall. Seven percent of dermoid cysts occur in the craniofacial region (5). Dermoids were topographically divided into three subgroups as frontotemporal region, occipital region and naso glabellar region by Bartlett et al., (6) in 1993. Dermoid cysts in the frontotemporal region are the most common subgroup and are located in the lateral eyebrow region. If not infected, they emerge as slow-growing asymptomatic masses. Dermoid cysts in this region and the orbital region are typically superficial lesions, but naso glabellar dermoid cysts, especially those under the nasofrontal suture line, often exhibit sinus tract and intracranial extension (7). In another study by Pryor et al., (8) they enrolled 49 pediatric patients and it was observed that dermoid cysts were mostly (61\%) seen in the periorbital region. In our study, the lesions were located in the periorbital region in $75.8 \%$ of the cases and in the medial canthal region in 3.4\% of the cases. In another study, dermoid cysts around the orbita were examined and dermoid cysts were found to be located $70 \%$ over the superotemporal-zygomaticotemporal suture, $20 \%$ over the superonasal maxillo frontal suture and $5 \%$ in the nasal soft tissue (9). Orbital dermoid cysts may exhibit ocular symptoms such as proptosis and limitation of eye movements. Dermoid cysts create a non-inflammatory mass effect, show a slow growth pattern and compress the surrounding tissues. Histologically, rupture is around $50 \%$ and low-grade inflammation is observed in surrounding tissues (9). Twenty percent of the dermoid cysts on the cranial midline show intracranial extension. Embryologically, they develop as a result of the continuation of the connection between the ectodermal and neuroectodermal structures during closure of the frontal and orbital segments at 8-9 weeks. Bone erosion can be seen in dermoid cysts especially in the periorbital region (10). In a study of 70 patients by Sathananthan et al., (11) bone erosion was found in $87 \%$ of the patients and full-thickness bone defect was detected in $34 \%$ of the patients.

In adult patients, preoperative imaging is more important because the cysts are larger and the probability of complications is higher. In our study, the size of the current mass was less than $2 \mathrm{~cm}$ in all cases and no intracranial involvement was observed.

\begin{tabular}{|l|l|l|l|}
\hline \multicolumn{4}{|l|}{ Table 2. Comparison between initial diagnoses based on preoperative imaging methods and postoperative pathology results } \\
\hline Number of case & Percent & Initial diagnosis on preoperative imaging (USG and MRI) & Postoperative pathology result \\
\hline 1 & $2.7 \%$ & Epidermal cyst? Dermoid cyst? & Juvenile hemangioma \\
\hline 1 & $2.7 \%$ & Epidermal cyst? Dermoid cyst? & Pilomatrixoma \\
\hline 6 & $16.2 \%$ & Epidermal cyst? Dermoid cyst? & Epidermoid cyst \\
\hline 29 & $82.8 \%$ & Epidermal cyst? Dermoid cyst? & Dermoid cyst \\
\hline 37 & $100 \%$ & - & \\
\hline USG: Ultrasonography MRI: Magnetic resonance imaging & \\
\hline
\end{tabular}


In only one case, a dermoid cyst on the lateral of the right eyebrow was fistulated into the orbita through the lateral wall of the orbita. That is why preoperative USG is sufficient and CT or MRI may not be used for lesions smaller than $2 \mathrm{~cm}$, localized in the frontotemporal region and especially seen in early ages. Although the initial diagnosis of dermoid cyst was established by clinical examination and USG in our patients and most of the localization was periorbital region, additional imaging studies such as CT and/or MRI were needed for differential diagnosis due to the inability to palpate these masses superficially. Regarding the treatment algorithm described by Chang et al., (3) for frontotemporal dermoid cysts in adult patients and approach to orbitofascial dermoids in pediatric population described by Bartlett et al., (6) we evaluated our patient population, size of mass and localization, then we established the examination and treatment algorithm shown in Table 3.

Although a congenital intracranial frontotemporal dermoid cyst may appear clinically as a cutaneous fistula in the first stage, intracranial extension and cutaneous sinus tract formation are rare in these dermoid cysts (12). Dermoid cysts in the scalp usually adhere to the periosteum and the normal diameter of the lesions is $1-4 \mathrm{~cm}$.

Dermoid cysts are rare in the head and neck region, but they should be included in the differential diagnosis of all nodular and cystic lesions in this region in infants and children. An intraoral nodular lesion or tongue tumor may be a dermoid cyst. A giant dermoid cyst in the neck can mimic the cystic hygroma and MRI is required for differentiation (13).

Although dermoid cyst was one of the initial diagnoses according to preoperative imaging reports in eight patients in our study, the final pathology results were not dermoid cysts. The pathology of these patients was reported as epidermoid cyst, juvenile hemangioma or pilomatrixoma. This shows that the gold standard in the diagnosis is the pathology. Trichilemmal cysts, pilomatrixomas, hemangiomas or epidermal cysts may be similar to dermoid cysts on imaging. Therefore, the most reliable way to diagnose and understand how deeply the lesion extends is to show the lesion during the operation and total excision of the cyst tissue. In addition, in contrast to epidermal inclusion cysts, dermoid cysts in the skin are covered with an epidermis with various epidermal extensions. As a rule, these extensions are fully matured. Hair follicles containing hairs entering the lumen of the cyst are often found. The dermis of the dermoid cysts usually contains sebaceous glands, eccrine glands, and apocrine glands in many patients. Surgical excision is the preferred treatment for cyst in any localization. In order to prevent recurrence, the total removal of the dermoid cyst is necessary so that no residual cyst tissue is left behind. In our study, no recurrence was observed in any patient.

Although the treatment of dermoid cysts is surgical, surgical planning should be performed after the physical examination and completion of radiological examination. Treatment should not be delayed as the lesion may cause psychological and social problems especially in children (14). Treatment is surgical

\section{Table 3. Treatment algorithm}

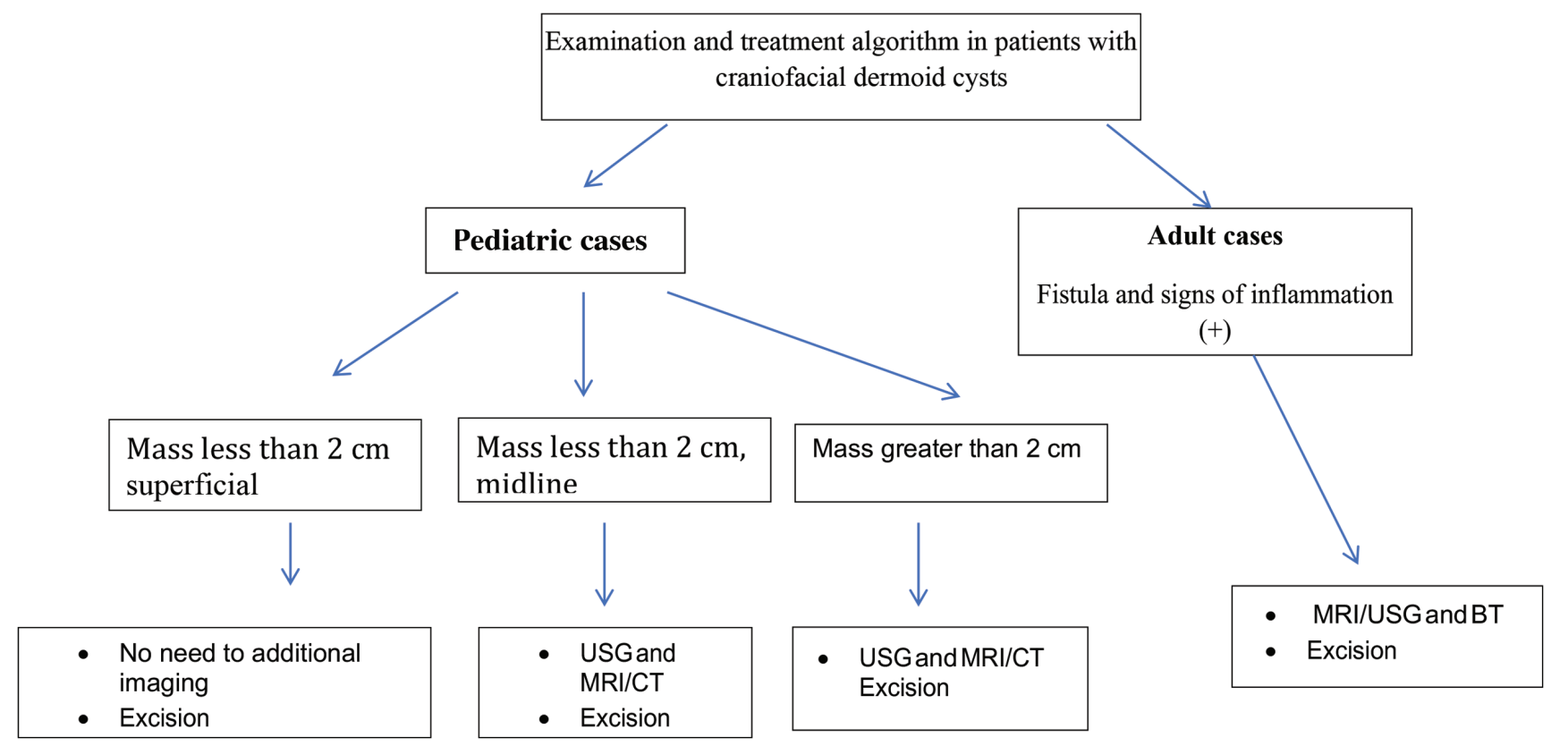


excision prior to rupture. The surgical procedure is determined by the extension of the mass and the age of the patient. There are many surgical approaches described in the literature. Some of these approaches are open septorhinoplasty, bi-orbitofrontal nasal craniotomy, anterior craniotomy with lateral nasal flap and total excision of the lesion with gull wing incisions $(15,16)$. There are many options described in the literature for repair of defects in the bone, including autogenous bone, cartilage and dermofat graft, alloplastic materials and allogenic grafts (15).

\section{CONCLUSION}

Dermoid cysts are excised not only for elimination of poor cosmetic appearance, but also for the prevention of possible discharge and infection, for definite pathological diagnosis and for prevention of secondary bone changes. It is important not to delay treatment because it may cause psychological and social problems in children and may cause bone erosion and defects in older ages.

\section{Ethics}

Ethics Committee Approval: Retrospective study.

Informed Consent: Retrospective study.

Peer-review: Externally peer-reviewed.

\section{Authorship Contributions}

Surgical and Medical Practices: Ö.Ç., I.Ü., Ö.Ö.M., Concept: Ö.Ç., i.Ü., A.E.S., Ö.Ö.M., Design: Ö.C.., I.Ü., A.E.S., Ö.Ö.M., Data Collection or Processing: I.Ü., A.A., A.E.Ş., Ö.Ö.M., Analysis or Interpretation: A.A., I.Ü., Ö.Ö.M., Literature Search: A.A., Ö.Ö.M., Writing: Ö.C.., A.A., Ö.Ö.M.

Conflict of Interest: No conflict of interest was declared by the authors.

Financial Disclosure: The authors declared that this study received no financial support.

\section{REFERENCES}

1. Reissis D, Pfaff MJ, Patel A, Steinbacher DM. Craniofacial dermoid cysts: histological analysis and inter-site comparison. Yale J Biol Med 2014;87:34957.

2. Sreetharan V, Kangesu L, Sommerlad BC. Atypical congenital dermoids of the face: a 25-year experience. J Plast Reconstr Aesthet Surg 2007;60:1025-9.

3. Chang JW, Yoon JS, Lee JH. The appropriate surgical approach to frontotemporal dermoid cysts in adult patients. Ann Plast Surg 2017;78:548.

4. Charrier JB, Rouillon I, Roger G, Denoyelle F, Josset P, Garabedian EN. Craniofacial dermoids: an embryological theory unifying nasal dermoid sinus cysts. Cleft Palate Craniofac J 2005;42:51-7.

5. Uppal HS, D'Souza AR, De R, Irving RM. Dermoid cyst of the infratemporal fossa. J Laryngol Otol 2002;116:150-2.

6. Bartlett SP, Lin KY, Grossman R, Katowitz J. The surgical management of orbitofacial dermoids in the pediatric patient. Plast Reconstr Surg 1993;91:1208-15.

7. Pensler JM, Bauer BS, Naidich TP. Craniofacial dermoids. Plast Reconstr Surg 1988:82:953-8

8. Pryor S, Lewis JE, Weawer AL, Orvidas LJ. Pediatric derrmoid cyst of the head and neck. Otolaryngology Head and Neck Surgery 2005;132:938-42.

9. Illke Bahçeci Şimșek Superonasal Dermoid Kist ve Kanaliküllerde Darlığa bağı Epifora İstanbul Medicine Hospital Olgu Sunumları Bakırköy Tıp Dergisi 2010;6:81-3.

10. Samuel M, Maurice MD, Fernando D, Burstein MD. Disappering dermoid: fact or fiction? J Craniofac Surg 2012;23: e31-3.

11. Sathananthan N, Moseley IF, Rose GE, Wright JE. The frequency and clinical significance of bone involvement in outer canthus dermoid cysts. Br J Ophthalmol 1993;77:789-94

12. Scolozzi P, Lombardi T, Jaques B. Congenital intracranial frontotempora dermoid cyst presenting as a cutaneous fistula. Head Neck 2005;27:429-32.

13. Ro EY, Thomas RM, Isaacson GC. Giant dermoid cyst of the neck can mimic a cystic hygroma: using MRI to differentiate cystic neck lesions. Int J Pediatr Otorhinolaryngol 2007;71:653-8.

14. Tatlidede S, Egemen 0, Ozkaya O, Erol O. Witch nose: an embarassing metaphor for nasal tip dermoid cysts. J Craniofac Surg 2011;22:1948-51.

15. Heval Selman Özkan, Saimer Irkören, Hüray Karaca. Nasal dermoid sinüs kisti olgusuna cerrahi yaklaşım. Olgu sunumu ADÜ Tıp Fak. Derg 2014;15;7981

16. Huisman TA, Schneider JF, Kellenberger CJ, Martin-Fiori E, Willi UV, Holzmann D. Devolepmental nasal midline masses in children:neurocardiological evoluation. Eur Radiol 2004;14:243-9. 